\section{ekf}

\title{
Ensuring knowledge continuity and elimination of employee turnover in organisations in the Czech Republic
}

\author{
Hana URBANCOVÁ, Czech University of Life Sciences in Prague \\ Lucie LINHARTOVÁ, College of Economics and Management ${ }^{\mathrm{ii}}$
}

\begin{abstract}
The goal of organisations is efficient management leading to the efficient use of time, the minimisation of errors and the improvement of the organisations' productivity. The article focuses on the factor of knowledge continuity, which can contribute strongly to productivity enhancement and simultaneously eliminate the impact of employee turnover and subsequent loss of knowledge of its employees. The purpose is to reveal the current approach in Czech organisations with regard to the causes of employee turnover and knowledge continuity as a critical part of human resource management and to formulate relevant recommendation. The data evaluated here has been obtained through two primary surveys of managers in organisations in the Czech Republic. The outcomes reveal that efficient management, based on applying techniques of knowledge management and knowledge continuity management, may eliminate the negative impact of employee turnover on the loss of knowledge in organisations. The utilization of knowledge held by knowledge employees can contribute to the improvement of efficiency of individual processes and in turn the productivity of the entire organisation. For management to be efficient, managers have to use suitable methods of employee leadership and to create conditions that support knowledge sharing, transfer and preservation. If appropriate conditions are established, employee turnover does not need to lead to the loss of knowledge possessed by knowledge employees.
\end{abstract}

\section{Keywords}

Employee turnover, knowledge continuity, knowledge management, knowledge worker.

JEL Classification: J53, J63

\footnotetext{
${ }^{\text {i }}$ Department of Management, Faculty of Economics and Management, Czech University of Life Sciences in Prague, Kamýcká 129, 16400 Praha 6 - Suchdol, Czech Republic.

ii Department of Management, College of Economics and Management, Nárožní 2600/9a, 15800 Prague 5, Czech Republic urbancova@pef.czu.cz (corresponding author)

This contribution is a follow-up to the project of University - wide internal grant agency (CIGA), number 20121001 - Business continuity management contributing to higher performance in organizations.
}

\section{Introduction}

The correct and efficient activity of managers is a way of achieving the goals of the given organisation. At present, organisations' managers strive to preserve the maximum amount of knowledge and prevent organisations from losing valuable and necessary knowledge (ensure continuity) in case the knowledge holder has left or is about to leave the organisation (Eucker, 2007; Miller, 2007; Haldin-Herrgard, 2000). Continuity is a characteristic that has always been related to knowledge, however, nowadays when the importance of knowledge for organisations is on the increase, organisations' managers should be monitored even more intensely. Managers should not only preserve knowledge and transfer it efficiently within the organ- 
isation, but also ensure that knowledge is not lost if knowledge employees decide to leave (Jenkins, 2009; Prevot, 2008; Johannessen and Olsen, 2003). In order to preserve an organisation's knowledge efficiently, it is necessary to integrate the so-called knowledge continuity area into the general management of the organisation. This article presents the outcomes of surveys targeted at employee turnover and ensuring knowledge continuity.

The aim of this article is to reveal the current approach in Czech organisations to the causes of employee turnover and ensuring knowledge continuity as critical part of human resource management, as well as to formulate relevant recommendation. The partial goal is to identify types of organisations with regard to their focus on employee mobility and thus knowledge continuity. Using a sample of managers, the second partial goal is to make proposals about how to eliminate the unsuitable practices which were found using background information from surveys. The third partial aim is to test dependencies between selected qualitative variables in relation to knowledge continuity, ensuring the process of employee turnover and confirming their validity or rejecting them at the selected significance level.

The article deals with ensuring knowledge continuity as a factor that can strengthen an organisation's management in order to reduce the negative consequences of staff turnover. Based on the literature review, the paper presents the results of primary surveys focused on the current situation in employee turnover management and the level of involvement of Czech organisations with regard to retaining talented employees and ensuring knowledge continuity. To validate the results, all the data will be presented together with statistical verification. The results will be presented in order to formulate suggestions for organisations to improve employee turnover management and ensuring knowledge continuity.

\section{Theoretical background of the work}

There are several trends occurring within the employment scene that suggest companies need to pay more attention to turnover and retention issues. It is important to note that employee turnover significantly affects overall financial performance (Bowes, 2010). Lowering of negative employee turnover depends mainly on human resources in the specific organisation, and on job relations, levels of satisfaction and the interest of management in the main reasons why employees leave (Branham, 2005; Deiblová, 2005; Heathfield, 2010; Reiß, 2008). Successful organisations accept responsibility for the atmosphere of the workplace (Zahorsky, 2010). It has been acknowledged that employees rarely leave their job position, even when they feel confident and their needs and wishes are satisfied, and even when better jobs are being offered in another organisation. Most of the staff prefer stability (Katcher and Snyder, 2007; Kocianová, 2010). Factors which contribute to employee turnover have to be recognised and an organisation has to develop strategies to overcome them (Bowes, 2010). The reasons for employee turnover can be eliminated by detection.

According to Anagnoste et al., (2010) and Bratianu (2008), at present organisations use the so-called transformation management that supports the resource-based approach and makes working with knowledge more efficient. By using transformation management, the quality of processes may be improved, efficiency enhanced (i.e. detection and elimination of bottlenecks in processes) and thus the prosperity (success) of a given organisation increased (Goldratt, 2009). Productivity is defined as the achievement of results by individuals or group or a measurement of an organisation and its processes (Nenadál, 2001; Brockmann and Simmonds, 1997). Transformation management is a process that changes and transforms people so that that every alteration made is valuable. Transformation takes place through emotions, values, ethics, standards, long-term goals, charisma, inspirational leadership, respect for an individual and intellectual stimulation and includes the assessment of employees' motives (Bratianu, 2008; Ramlall, 2004). This management style is based on meeting the higher needs of employees. It leads to self-fulfilment, self-regulation and self-control. It creates needs among employees of which they were not previously aware. Transformation can be achieved by three means (Anagnoste et al., 2010; Bratianu, 2008; Ramlall, 2004):

- By improving the level of awareness of the significance and value of work outcomes and methods of their achievement

- By stimulating people to transmit their interests into the interests of their team or organisation

- By changing the needs, as in Maslow's hierarchy or by broadening the current spectrum of needs

By encouraging and proper application of the above-mentioned methods which support transformation management by organisations' managers, it is possible to achieve a better process of sharing, transferring and preservation of the knowledge held by knowledge employees in these organisations.

A manager, i.e. an employee who is responsible for the implementation or progress of certain activities and goal achievement by the organisation, is also a knowledge employee. To be able to perform their job, they need certain knowledge, skills and character- 
istics. For the purpose of this contribution, three levels of management, and therefore three types of managers, are recognised:

- Management at the basic level, line managers (lower/operational/management)

- Middle management, middle-level managers (middle management)

- The highest management level, top manager (top management) (Somaya and Williamson, 2008; Bělohlávek et al., 2001).

Apart from the number of employees (moving towards top management the number of employees diminishes; the top position in the organisation being occupied by one single manager), individual levels of management also differ in the main focus of their activities. Top management is characterised by the predominance of strategic activities. Top managers are responsible for the overall performance of their organisation. The middle level of management has a predominantly tactical nature. Middle managers implement plans and strategic goals of the organisation's management by co-ordinating the tasks performed in a way to achieve the organisation's preset goals. The lowest level of management is commonly dominated by operational management activities (Shih and Chiang, 2005; Bělohlávek et al., 2001; Bedrnová et al., 1998). Nonaka and Takeuchi (1995) prescribe each management level a different role in working with knowledge. Employees and lower management (i.e. the lowest positions) play the role of knowledge implementators while middle management consists of knowledge engineers whose task is to transform tacit into explicit knowledge. They are therefore irreplaceable. Top managers hold the position of knowledge managers who are responsible for the management of knowledge at the organisational level (Miller, 2007; Harsh, 2009).

Nonaka (1991) asserts that personal involvement and the identification of knowledge employees with the organisation and its mission are essential for knowledge generation. Cabrera et al. (2006) state that individuals who identify with an organisation's goals and culture will make a greater effort to share their knowledge with colleagues. Organisations have begun to realize that, in an ever-faster competitive environment, they cannot rely solely on their size and capital strength, but need to rely primarily on their employees, i.e. knowledge employees. People who dispose of knowledge and know how to use it will constitute the only competitive advantage for each organisation (Kachaňáková and Stachová, 2011). The new trend of knowledge management (the transfer of knowledge among existing employees) and knowledge continuity (the branch of knowledge management aiming at achieving knowledge transfer by leaving employees to their successors) is also presented based on this.

One of the conclusions of the article is the fact that ignoring the existence of knowledge continuity in today's economic situation could result in inefficient management that neglects competitive advantage driven by knowledge and subsequently leads to the loss of knowledge held by departing knowledge employees. In the end, this could cause a decrease in the organisation's productivity (Wong, 2009).

\section{Materials and methods}

The aim of the paper is to reveal the current approach in Czech organisations to causes of employee turnover and knowledge continuity as a critical part of human resource management and to formulate relevant recommendations.

The first part of the article deals with theoretical approaches to issues of turnover and knowledge continuity in organisations while the second part analyses the findings of surveys carried out in the Czech Republic. The article has been processed based on the analysis of secondary sources, outcome synthesis and the evaluation of results of a questionnaire survey. With respect to the fact that the data collected was obtained on a selective basis, it was necessary to determine whether they were dependent attributes and whether the findings could be generalised and applied to the basic group.

Based on the literature review, the determinants of reasons of employee turnover were deducted and main factors constructed. In two successive surveys 29 determinants ${ }^{1}$ were used to describe 7 main factors causing employee turnover. Those factors are remuneration, certainty, relationships, recognition, communication, culture and expectations. The factors were confirmed by the method of induction based on the results of the surveys. For reasons of provable clear understanding, the factors were structured as being, analogically to the survey carried out by Gosling et al. (2003), John et al., (2008) and Benet-Martinez and John (1998). The conclusiveness of the outcomes was supported by aggregation; by adding individually tested items the superordinate item and the whole were supported. ${ }^{2}$ The conclusiveness of factors and their determinants was tested by means of a correlation analysis at the significance level of 0.01 . The

\footnotetext{
1 Statements used by the respondents to characterize the main reasons to leave.

${ }^{2}$ Individual items of the construct sustaining final factors were tested separately and their reliability was added up in the whole.
} 
outcomes indicate a direct and strong dependence between employee dissatisfaction with the identified factors and the decision to leave their work position. The factors were therefore used for further analyses.

The surveys focused on employees were completed by 100 respondents who left their jobs last year. Employees were surveyed to found hidden reasons to leave the organisation. The method used for data collection in the first survey was CAWI (computerassisted web interviewing). The second, control questionnaire was based on the CATI method (computer-assisted telephone interviewing). The selection of a representative sample of employee population across sectors was carried out by contacting a random selection of telephone numbers (from numbers registered at the Czech telecommunication office ${ }^{3}$ ), which incorporates the advantages of multilevel random selection (Disman, 2008). The sample was selected solely for the purposes of the survey and included employees or managers in the age category 20 to 55 who had left their job in the course of the past twelve months. The measurement was based on closed questions with one or several possible answer(s) (Hayes, 1998) that had been selected based on the study of literature, documents and other related surveys carried out by the following authors: Branham (2005), Hackman and Oldham (1980), Meyer and Allen (1991) and Katcher and Snyder (2007).

One additional research focus on managers took a part of the whole study to compare views of both parts of work process. The third type of questioning focused on managers and used the same topics as were used in the first and second survey. Special attention was focused on use of information about employee turnover, knowledge of why employees leave and if an organisation takes care about costing employee turnover and wishes to keep trained employees. Questions were open and managers could speak about the theme. The respondents were selected from various sectors in order to create a representative sample. The analysis was carried out using the Microsoft Excel 2007 and SPSS programmes. The conclusiveness of the outputs and relationships obtained were supported by the tools of descriptive statistics, the analysis of dispersion, parametric tests and correlation, regression and determination, which were used to review the outcomes.

The data for the evaluation of relationships between identification variables in area knowledge continuity ensuring were gathered by using a quantita-

\footnotetext{
${ }^{3}$ Respondents were firstly asked if they willingly left their last job in past 12 months. If agree, they took a part of the survey.
}

tive survey, i.e. a questionnaire survey, in which 167 higher and middle management managers from various organisations took part/ The branch from which the organisations operate was been taken into account. The questionnaire contained 19 questions (15 closed and 4 semi-open) on the knowledge sharing and knowledge transfer and 8 identification questions. The questionnaire was distributed to 814 respondents. The overall questionnaire return was $20.52 \%$, i.e. 167 respondents took part. 55.1\% holds a senior management position, $68.9 \%$ have university education, $45.5 \%$ are in the age group $46-62$ years, $70.1 \%$ are employees of Czech organisations, $51.5 \%$ work in tertiary sector and $38.9 \%$ work in the primary sector. $76.6 \%$ of respondents were male. For a selective set of questionnaires of managers (167) at the middle and higher levels of management, the prevalence of men in managerial positions over female managers in organisations in the Czech Republic can be statistically supported by data from the Czech Statistical Office (CSO). According to the CSO, in $200977.5 \%$ of higher managerial positions were held by men, while female employees occupied only $22.5 \%$ of these positions, which also confirms the structure of respondents in the survey carried out in 2010. Women are more frequently appointed to positions in lower management.

The survey was focused on managers:

- Who were part of managerial units (liable for the running of the organisation or group performance) that were focused, on an increasing scale, on sharing, transferring and preserving of knowledge of employees who were about to retire or leave to join a competitor (responsible for knowledge transfer in the organisation).

- Working with knowledge base and with the aim to enhance it.

- Who themselves were knowledge employees with critical knowledge or monitored employees with such critical knowledge.

The data were processed by means of absolute and relative frequencies using the Lime Survey application and the Excel 2007 programme. Testing was done by Pearson Chi-Square test in association table and contingency table. The power of dependence was determined by the correlation coefficient and Cramer's coefficient. The presented results could be generalized on selected sample.

\section{Results}

In this section, we will describe findings from the primary surveys regarding causes of employee turnover in consequence with knowledge continuity ensur- 
ing. The results of statistical tests and analyses are presented below.

\subsection{Working with information about the causes of employee turnover in organisations}

The results of a survey focused on use of information, rate, time series, reasons and consequences of turnover in organisations are stated in Table 1. It is clear that reference sample of organisations do not work with leaving interviews and possibilities, which are hidden in the monitoring of employee turnover.

Table 1 Monitoring of turnover in organisations

\begin{tabular}{|l|c|c|c|c|}
\hline \multirow{2}{*}{ Workflow } & \multicolumn{2}{|c|}{ Yes } & \multicolumn{2}{c|}{ No } \\
\cline { 2 - 5 } & $\begin{array}{c}\text { Abso- } \\
\text { lute }\end{array}$ & $\%$ & $\begin{array}{c}\text { Abso- } \\
\text { lute }\end{array}$ & $\%$ \\
\hline Use of leaving interview & 14 & 45 & 17 & 55 \\
\hline $\begin{array}{l}\text { Retention of results of leaving } \\
\text { interviews }\end{array}$ & 17 & 55 & 14 & 45 \\
\hline $\begin{array}{l}\text { Leaving interview initiated by } \\
\text { supervisor }\end{array}$ & 21 & 68 & 10 & 32 \\
\hline Costing of employee turnover & 20 & 65 & 11 & 35 \\
\hline Use of employee turnover rate & 14 & 45 & 17 & 55 \\
\hline $\begin{array}{l}\text { Use of time series of employee } \\
\text { turnover }\end{array}$ & 9 & 29 & 22 & 71 \\
\hline $\begin{array}{l}\text { Individual evaluation of turnover } \\
\text { rate for managers/departments }\end{array}$ & 8 & 26 & 23 & 74 \\
\hline $\begin{array}{l}\text { Comparison of manag- } \\
\text { ers/departments }\end{array}$ & 3 & 10 & 28 & 90 \\
\hline $\begin{array}{l}\text { Use of results and ups downs of } \\
\text { turnover }\end{array}$ & 8 & 26 & 23 & 74 \\
\hline $\begin{array}{l}\text { Monitoring of costs and incomes } \\
\text { per employee }\end{array}$ & 14 & 45 & 17 & 55 \\
\hline $\begin{array}{l}\text { Unexpected leaves of employees } \\
\text { are common }\end{array}$ & 14 & 45 & 17 & 55 \\
\hline $\begin{array}{l}\text { Discussion upon comments of } \\
\text { leaving employees }\end{array}$ & 30 & 97 & 1 & 3 \\
\hline $\begin{array}{l}\text { Effort to maintain trained } \\
\text { employees }\end{array}$ & 22 & 71 & 9 & 29 \\
\hline Average 5 & 48 & - & 52 \\
\hline
\end{tabular}

Organisations tested in a survey used leaving interviews in just $45 \%$ of all cases. That implies the existence of great reserves in retention management in organisations in Czech Republic. Thus, other catego-

\footnotetext{
4 Absolute number of surveyed organisations. The total number of surveyed managers was recalculated with regard to the number of organisations surveyed. Thus absolute number characterizes the sum of different types of organisations.

${ }^{5}$ The average was calculated as being the sum of all items related to the monitoring of turnover in organisations (percents of usage) and divided by total number of studied workflows presented in the Table 1 . The average stands for average monitoring of turnover and use of workflows mentioned in organisations surveyed.
}

ries related to the monitoring of employee turnover are dependent on using leaving evaluation forms. If an organisation does not work with leaving interviews, it is rarely expected that it would be deeply interested in retention management, because in such an organisation, the most important tool and information source is not being used for further analyses and results. The results of leaving interviews were saved in organisations in $55 \%$ of cases, but nobody was working with them and exploring their potential uses (use of leaving interviews and related information was $10 \%$ lower than saved ones). If organisations do not use leaving interviews, they lose not just money and time spent on the leaving interviews but also time and money wasted on formal meetings with employees and supervisor which is meaningless and does not help to one or another. All persons related to this senseless just spent their time with no reason and organisation pay for this wasted time to all participants, which unnecessarily higher personal cost. Referred sample of managers mentioned that leaving interview is usually initiated by supervisor of leaving employee, because of prescription of internal organisation rules. But as it is possible to see in Table 1, leaving interview is commonly used in just $68 \%$ of monitored organisations, the rest of managers do not use leaving interview and employees leave without getting feedback to the organisation.

Costing of turnover is regarding to the answers of monitored managers is used in $65 \%$ of organisations. This implies a higher awareness of the necessity to monitor turnover and its impact on an organisation, but $35 \%$ of organisations still do not appear to be concerned about turnover costs and do not have any overview of the amount of loses which are caused by this phenomenon. The fact that some organisations carry out costing of turnover but do not pay attention to information from leaving interviews is bewildering. This shows that supervisors only formally follow the rules of the organisation but do not analyse the situation in order to eliminate negative practices and thus lower turnover and its costs. Turnover rate is being used by only $45 \%$ of managers being referred. This shows that $49 \%$ of managers do not have any idea about turnover rate in the organisation or department where they work. Ignorance of turnover rate also suggest no possibility of counting turnover costs and this confirms assumption that costing of turnover is only a formally mandated obligation, which does not reflect the real situation in organisations.

Following four monitored items in Table 1 (Use of time series of employee turnover, Individual evaluation of turnover rate for managers/departments, Comparison of managers/departments and Use of results and ups downs of employee turnover) follow the overall ignorance of turnover rate in organisations 
and prove inadequate use of the potential which is hidden in the reports from leaving employees. Time series are used in less than one third of referred organisations; $71 \%$ of organisations do not have any overview about changes of turnover or if it for example reaches a tolerable or long term maximum or if it comes to a situation which requires intervention. Individual evaluation of departments or managers is used only in $26 \%$ of cases, $74 \%$ of sample cannot tell, if there are for example only one or a few problematic managers, where intervention into a few persons behaviour could solve the entire situation without the need to change of the whole corporate culture or to create innovation in organisational processes. Organisations should focus on achieving thorough recognition of the real source of problems, because small local change is considerably less expensive than changing the whole or a large part of an organisation. The suggestion also supports the statement of managers that individual evaluation of departments or managers are needed only in $10 \%$ of cases and the vast majority of findings stay unused because results and turnovers claims only $26 \%$ of referred organisations. Again, it is possible to recognize the bureaucracy of organisation in the monitoring of turnover. Managers only carry out their work and follow internal rules with no insight or knowledge about why are they doing so and results are not used in three quarters of organisations.

The costs-benefit ratio per employee and his/her potential utility and value for an organisation as an amount of potential loss if the organisation would lose that employee is monitored in $45 \%$ of organisations. More than half of firms do not have any view about how and which employees are beneficial and productive. This can provoke a lack of involvement in recognition if it is better for an organisation to dismiss an employee as he/she is no longer beneficial to the organisation and can be easily replaced by other more suitable employees if he/she shows an interest of leaving the company and they try to convince him/her to stay. Monitoring of the cost-benefit ratio is suggested to organisations not just because of turnover and retention decisions, but also for purposes of performance management. It is surprising that such a useful tool is only being used in half of the organisations.

Managers know their subordinates and pay attention to them only in $50 \%$ of cases; $45 \%$ of the managers confirmed that their employees would often leave job positions suddenly without warning. Low knowledge of subordinates or disregard of impulses from disaffected employees could be the reason. On the other hand, almost all referred managers (97\%) stated that they discuss comments with leaving employees. As it is possible to see in Table 1, those comments are most probably never used. It is only a formal affair, which does not lead to desired change. The survey proves this; $71 \%$ of employees stated that they discussed their real reasons for leaving with their supervisor or other managers in the organisation, but that nothing had been offered to them which would change the situation and make them stay (in 76\%). This was counterproductive, because $54 \%$ of referred employees were open to changing their mind during the period of decision if the inconvenient conditions were changed or eliminated.

Moreover, $71 \%$ of managers stated that an effort had been made to keep tranied employees. This percentage is relatively high, but it is a result of prevailing attitudes, because the above mentioned analysis of the current situation implies that managers do not know anything about their subordinates, do not monitor reasons for their disaffection and getting into conflict situations. The managers are perceived not to care about their feelings, so employees leave suddenly. On the other hand, in $71 \%$ of cases employees stated that the organisation did not try to stop them leaving. Thus it is possible to say that the statement of managers that they try to maintain employees is generally overstated.

\subsection{Knowledge continuity ensuring in organisa- tions}

The largest group of managers contacted hold a higher management position, have a university degree, belong to the 46-62 age group, lead teams of up to 5 employees and are primarily employed by Czech organisations. The survey has also shown that all managers share their knowledge with their colleagues in the organization. However, the extent of sharing differs. 45 respondents $(26.9 \%)$ said that they shared knowledge, but not all of it as they were the only ones who could have such knowledge. This group consisted of auditors and IT employees with security clearance who, in order to perform their job needed a certificate reflecting the education, experience and practice of the given person. Other managers $(17.4 \%)$ responded that they shared only part of their knowledge as they wanted to maintain a certain advantage of knowledge ownership and to have a competitive advantage compared to others. Only $55.7 \%$ of respondents tried to share all their knowledge.

A total of 149 managers out of $167(89.2 \%)$ were willing to train a young promising employee who could become their successor. In total, $44.9 \%$ of respondents had some experience with a mentor who provided them with initial training at the beginning of their management career. These respondents truly appreciated the co-operation with their mentor. Also $74.9 \%$ of respondents said that it was impossible to perform a managerial position without previous training assisted by a more experienced employee. 
Only $25.1 \%$ of respondents started their position without being trained by another employee.

A total of $54.5 \%$ managers mentioned that they had experience of knowledge and experience recording within the frame of their position, but only to a limited extent (e.g. without knowledge that would deprive them of their competitive advantage). $85.6 \%$ of respondents recorded knowledge and experience associated with their position and $76 \%$ of respondents also recorded knowledge and experience of their subordinates. $40.1 \%$ of respondents stated that they elicited and recorded knowledge of their subordinates on their own initiative while $35.9 \%$ said that this was a company regulation. The majority of organisations for which respondents work use knowledge databases. The survey has shown that $33.5 \%$ of respondents' organisations employ, in the long run, special tools and databases designed for recording employees' knowledge and experience. A total of $38.3 \%$ of respondents stated that they did use such tools but only from time to time and that this activity had no prescribed form. Other respondents stated that they had no such tools at their disposal and therefore did not apply them.

The survey also revealed that a total of $70.1 \%$ of respondents (117 managers) transfer knowledge to other employees because it gives them a feeling of satisfaction if knowledge is spread across the organisation (so-called altruism). For $25.7 \%$ of respondents the most important reason for knowledge transfer is the expectation that if they provide a piece of knowledge to someone, in the future (when they need it) they will be provided with a piece of knowledge in return - so-called reciprocity. Only $4.2 \%$ of managers stated that their reason for knowledge transfer is the improvement of their image (reputation).

When an employee retires or leaves to join a competitor, organisations provide a successor in $66.5 \%$ of cases. This is to ensure that the successor will take over the employee's knowledge and experience. Another 34 managers $(20.4 \%)$ stated that when someone was due to leave, they elicited and recorded his/her selected (critical) knowledge and experience that was crucial for the given organisation.

Also, $61.7 \%$ of managers were motivated to transfer knowledge to their successors when they leave an organisation, out of which $38.3 \%$ stated that they were stimulated by the organisation to share and transfer knowledge. Managers were also given the option to state how they were stimulated and subsequently motivated to share, transfer and preserve knowledge and experience. For example, 13 respondents mentioned a financial bonus for the leaving employee. Two out of these respondents mentioned that they also imposed financial penalties in the event that the leaving employee was unwilling to transfer the position-related knowledge and experience to their successor. Four respondents stated that this area was part of their organisational culture. Other managers (36) responded that knowledge and experience sharing, transfer and preservation (document archiving, handover document drafting, database completion, successor training, checking (supervising) the trained successor, etc.) was requested from a leaving employee. However, this was not anchored in the organisational culture. If knowledge continuity ensuring was not part of the organisational culture, organisations relied on a good long-term working relationship with the leaving employee at his/her workplace and personal arrangements through which the employee would be encouraged to train his/her successor.

Based on the information obtained from the questionnaire, it is possible to say that organisations place more emphasis on the transfer of tacit rather than explicit knowledge (which is easier to obtain and transfer). The survey has demonstrated that tacit knowledge is usually transferred through informal meetings in organizations, as mentioned by 59 respondents (i.e. $35.3 \%$ ). To transfer explicit knowledge, e-learning applications are used in the majority of cases.

A total of $73 \%$ of respondents said that if an employee with critical knowledge left, this would threaten the organisation. $39.5 \%$ of these respondents (i.e. 66) stated that the organisation would be jeopardised by a leaving employee with critical knowledge because the organisation would lose the knowledge while $33.5 \%$ of respondents mentioned the threat of utilization of the knowledge by their competitor.

The results of the article provide 13 hypotheses leading to the fulfilment of the set goal. Of the given zero hypotheses, 8 have been rejected, i.e. there is a dependency between the qualitative attributes examined, while 5 zero hypotheses could not have been rejected, i.e. there is no dependency between the qualitative attributes examined. The results of testing the below mentioned working hypotheses are shown in Table 2.

Statistical tests show that the experience with knowledge continuity ensuring is not dependent on the sector, but is on the size of the organisation, i.e. respondents from large organisations have more experience in this area compared to respondents from smaller organisations. In total $50.3 \%$ of managers included in the survey responded that they had never come across the idea of ensuring knowledge continuity. It is therefore possible to say that the issue of ensuring knowledge continuity has not been on the agenda of the selected group of managers. The highest number of managers $(71.7 \%)$ had at least once expe- 
rienced knowledge continuity, ensuring work in organisations with more than 250 employees.

According to the results of the survey, the zero hypothesis that knowledge sharing is not determined by sector has not been rejected either. The survey has also revealed that managers' experience with mentors is determined by their age. The scope of recording of subordinates' knowledge is dependent on the size of the organisation and the number of direct subordinates. It is also dependent on whether it is a Czech or foreign organisation; foreign organisations tend to record knowledge more than Czech organisations.

Neither has the dependency between the positionrelated knowledge and experience recording and the recording of subordinates' knowledge been rejected. Dependency has been determined between the qualitative attributes examined, i.e. a respondent who does not record knowledge and experience within his/her position in the organisation, neither elicits or records subordinates' knowledge and experience. Recording position-related knowledge, however, does not depend on the period spent in office.

The extent to which employees are stimulated to transfer knowledge and experience is determined by the size of the given organisation. The results show that the strongest stimulation and in turn motivation is provided to employees in large organisations $(65.2 \%)$, followed by small organisations of up to 19 employees $(26.8 \%)$ and then organisations employing from 20 to 99 employees. The reason for knowledge transfer, however, is not influenced by the sector and the willingness to train successors does not depend on the period spent in office.

Whether respondents perceive an employee's leaving as a threat to the organisation depends on the origin of the organisation (Czech, foreign), its size and the sector in which the given organisation operates. The survey has shown that a total of $29.1 \%$ of respondents in Czech organisations think that if an employee with critical knowledge leaves, this represents a threat to the organisation. The same applies to $64 \%$ of respondents from foreign organisations or organisations with Czech participation. 44 respondents (37.6\%) from Czech organisations and 12 respondents $(24 \%)$ think organisations are jeopardized by the utilization of the employee's knowledge by competitors. The results show that the majority of respondents who think that the leaving of an employee with critical knowledge is a threat for organisations are employees in organisations with over 250 employees, followed by organisation with up to 19 employees. The threat of utilization of knowledge by competitors is evident primarily in organisations with up to 19 employees. A total of $47.7 \%$ of respondents from the tertiary

Table 2 Testing among selected qualitative characteristics

\begin{tabular}{|c|c|c|c|c|c|}
\hline No. & Null hypothesis & $\begin{array}{c}p \text { value } \\
\chi^{2}\end{array}$ & $\begin{array}{l}\text { Denial } \\
\text { H0 }\end{array}$ & $\begin{array}{c}\text { Value of } \\
\text { depend- } \\
\text { ence }\end{array}$ & $\begin{array}{c}\text { Depend- } \\
\text { ence }\end{array}$ \\
\hline 1 & Experience with knowledge continuity ensuring is not depend on the sector. & 0.371 & no & $\mathrm{x}$ & $\mathrm{x}$ \\
\hline 2 & $\begin{array}{l}\text { Experience with knowledge continuity ensuring is not depend on the size of the } \\
\text { organisation. }\end{array}$ & 0.001 & yes & 0.323 & middle \\
\hline 3 & Knowledge sharing in the organisation is not depend on the sector. & 0.494 & no & $\mathrm{x}$ & $\mathrm{x}$ \\
\hline 4 & $\begin{array}{l}\text { Experience of respondents with mentor which allowed them to learn from his/her } \\
\text { experience is not depend on age of respondents. }\end{array}$ & 0.015 & yes & 0.188 & weak \\
\hline 5 & $\begin{array}{l}\text { Recording of knowledge within the position is not depend on recording the } \\
\text { knowledge of subordinates. }\end{array}$ & 0.007 & yes & 0.291 & weak \\
\hline 6 & $\begin{array}{l}\text { Recording of knowledge within the position is not depend on the length of the } \\
\text { position held. }\end{array}$ & 0.377 & no & $\mathrm{x}$ & $\mathrm{x}$ \\
\hline 7 & $\begin{array}{l}\text { The use of instruments to record the knowledge subordinates is not depend on the } \\
\text { size of the organisation. }\end{array}$ & 0.042 & yes & 0.280 & weak \\
\hline 8 & $\begin{array}{l}\text { The use of instruments to record the knowledge subordinates is not depend on the } \\
\text { number of direct reports. }\end{array}$ & 0.031 & yes & 0.204 & weak \\
\hline 9 & $\begin{array}{l}\text { Stimulating of leaving workers with critical knowledge is not depend on the size of } \\
\text { the organisation. }\end{array}$ & 0.000 & yes & 0.354 & middle \\
\hline 10 & The reason for the transfer of knowledge is not depend on the sector. & 0.315 & no & $\mathrm{x}$ & $\mathrm{x}$ \\
\hline 11 & Willingness from learn of successor is not depend on the length of the position held. & 0.425 & no & $\mathrm{x}$ & $\mathrm{x}$ \\
\hline 12 & $\begin{array}{l}\text { A threat arising from the leaving of an employee with critical knowledge for the } \\
\text { organisation is dependent on the sector. }\end{array}$ & 0.037 & yes & 0.248 & weak \\
\hline 13 & $\begin{array}{l}\text { A threat arising from the leaving of an employee with critical knowledge for the } \\
\text { organisation is not dependent on the size of the organisation. }\end{array}$ & 0.005 & yes & 0.332 & middle \\
\hline
\end{tabular}


sector think that the leaving of an employee with critical knowledge represents a threat to organisations and $31.4 \%$ think the threat lies in the utilization of that knowledge by competitors. The second most numerous category is that of the primary sector, where $29.2 \%$ were convinced that it indicates a threat and $32.3 \%$ were concerned by the possibility that the knowledge would be used by competitors.

\subsection{The importance of knowledge continuity for management of organisation}

The purpose of the management process is to enhance an organisation's productivity and one of the ways to achieve this is high quality human resources management, including efficient knowledge management. The knowledge of individual employees (teams) determines the productivity of the given department and in turn the productivity of individual departments determines the productivity of the organisation. Individual managers in organisations should realize this and lead individual teams in a way that will encourage employees to share, transfer and preserve knowledge and thus contribute to the efficient management of the organisation as a whole.

It is important to realise that general organisational strategy consists of individual strategies that need to support the overall strategy of the organisation. These strategies refer, for example, to the following areas: information, personnel, production and ensuring business activity continuity. Individual strategies should be optimised with the aim of creating a synergic effect and achieving fulfilment of the general organisational strategy. Simultaneously, applying personnel strategy and knowledge strategy can contribute to the fulfilment of the general organisational strategy.

The strategy is also supported by organisational culture and it is important to realize that if organisational culture fails to encourage knowledge continuity, knowledge and experience of individual employees will not be fully used and organisational knowledge will not be enhanced. Therefore the area of knowledge continuity ensuring should go hand in hand with the general strategy of the organisation and its organisational structure. It is therefore possible to say that knowledge continuity influences the strategy and its ensuring is important for the strategic management of the organisation.

\section{Discussion}

Organisations' managers have started to realize that in an increasingly competitive environment they cannot rely solely on the size of the organisation and its capital strength, but need to focus primarily on their employees, i.e. knowledge employees who are holders of both explicit and tacit knowledge.

Managers are knowledge employees as they lead their teams towards set goals. They also need certain knowledge, skills and characteristics to perform their jobs and these need to be developed on a continuous basis. Their work potential, which creates a competitive advantage in the business environment, needs to be improved. Managers need to stimulate and subsequently internally motivate knowledge employees to transfer knowledge to their successors in order to ensure knowledge continuity. If they fail to ensure it, this can inhibit productivity.

Knowledge continuity ensuring, i.e. the transfer of key knowledge from a leaving employee to his/her successor, is necessary in relation to employees who are crucial for the fulfilment of an organisation's main goals and who are highly in demand in the labour market (a situation which is not favourable for the organisation). From the organisation's perspective, these employees are the most endangered and it is particularly necessary to determine the causes of turnover of these employees and consider tools for their retention. Subsequently it is necessary to ensure knowledge continuity to preserve their knowledge and prevent its loss, provided they leave the organisation.

Today's information and knowledge oriented economy places a strong emphasis on intellectual and knowledge assets. An efficiently implemented conception of knowledge management and knowledge continuity management will enable an organisation to achieve improvements in the following areas:

Reinforcement and acceleration of company processes thanks to the reduction or elimination of redundant operations.

- Acceleration and enhancement of innovations thanks to free internal flow of ideas and notions.

- Reduction of employee turnover thanks to their greater involvement in company knowledge processes.

- Improvement of customer service by responding more efficiently to customers' needs.

- Improving the procedures by shortening the product development phase and the time before its launch on the market.

These conceptions are determined by the individual employees as the organisation uses their education, experience, knowledge and abilities. This is closely connected with the increasingly repeated term 'knowledge economy'. We can provide a comparison of the amount of investment in knowledge and investment in machinery and equipment incurred by the Czech Republic and its neighbouring countries. In the 
Czech Republic this amounts to $19.6 \%$. However, the average figure in the European Union is $44 \%$. Some of the countries in the European Union have a true knowledge economy - in particular Finland (73.3 \%) and Sweden $(82.8 \%)$. This fact also contributes to the complexity of perception of efficient knowledge management in organisations, with particular respect to minimising the loss of knowledge in the event of qualified employee turnover.

\section{Conclusion}

An analysis of practical use of employee turnover rates in organisations revealed an overview of structure and relations between the organisational practices used to monitor employee satisfaction and the disaffection which leads to turnover. Relations between monitored practices in organisations give us four possible approaches to employee turnover. Firstly, managers only formally monitor employee turnover, in order to follow internal organisational rules. They interview employees as requested, and save the results, but nobody uses or analyses them and they do not affect the consequential turnover rate. Secondly, attitude is characterized by deeper analysis of results of leaving interviews, address comments, time series analyses and solving of problems caused by attitudes of single managers or departments in order to eliminate negative turnover which was already found in organisation. Thirdly, a group of organisations profiled from those who are trying to avoid negative turnover rate by the deep knowledge analysed from leaving interviews and employees' comments and impulses, following a time series and other analyses and tests to apply the results. Fourthly, a group of organisations (which is relatively large - on average $52 \%$ of all referred organisations) does not use leaving interviews or any other forms of monitoring of employee turnover. Thus, turnover is not usually managed in referred organisations and the effort to objectively solve negative employee turnover is applicable only to minimum of referred managers. Thus, intervention in the system of turnover management is suggested, together with a top management's greater emphasis to already existing practices, which are very often ignored by the line managers.

At present, organisations place considerable emphasis on the knowledge and skills of their managers. Due to the high level of turnover in the labour market, organisations sometimes have to face the fact that senior managers will refuse to transfer knowledge to newcomers. Turnover can also have a positive impact too as taking on a new employee can lead to better performance, but unfortunately we are not able to determine how long this will last. Therefore it is necessary for managers to ensure sufficient transfer and sharing of knowledge and the experience of employees who are holders of critical knowledge in the given organisation and may represent a threat to the organisation's results. Employee turnover is a natural phenomenon. However, it is important to determine its causes. To ensure efficient HRM, such determination requires co-operation on the part of managers and human resources specialists.

The basic elements of successful management, including eliminating employee turnover and ensuring knowledge continuity for organisations can be described by three important ideas: finding people who have knowledge and are willing to share it (ask and listen); implementing processes to simplify knowledge sharing, and verifying and extracting elements of the common reliable technological infrastructure permitting knowledge sharing.

This paper has examined the current approaches of Czech organisations to employee turnover and thus knowledge continuity. Less than half of the monitored organisations could be seen to be taking sufficient care regarding the effects of mobility and in ensure knowledge continuity. It can be suggested, therefore, that the rest of the organisations need to improve their approach to leaving employees (i.e. to monitor employee turnover, conduct leaving interviews and examine their results) in order to retain talented employees and to ensure that effective knowledge sharing occurs. In conclusion, it is also possible to say that ensuring knowledge continuity helps to eliminate the negative elements in the turnover of knowledge employees.

\section{References}

ANAGNOSTE, S., AGOSTON, S., PUIA, R. (2010). Transformational leadership as a tool of knowledge dynamics. In: Proceedings of the 2nd European Conference on Intellectual Capital. Lisabon: ISCTE Lisbon University Institute, 54-58.

BEDRNOVÁ E., et al. (1998). Psychologie a sociologie rízení. Praha: Management Press.

BĚLOHLÁVEK, F., KOŠŤAN, P., ŠULEŘ, O. (2001). Management. Olomouc: Rubico.

BENET-MARTINEZ, V., JOHN, O. P. (1998). Los Cinco Grandes across cultures and ethnic groups: multitrait multimethod analyses of the big five in Spanish and English. Journal of Personality and Social Psychology 75(3): 729-750.

http://dx.doi.org/10.1037/0022-3514.75.3.729

BRANHAM, L. (2005). The 7 Hidden Reasons Employees Leave. New York: Amacom.

BRATIANU, C. (2008). A dynamic structure of the organizational intellectual capital. In: Naaranoja, M.: Knowledge Management in Organizations, 233-243. 
BROCKMANN, E., SIMMONDS, P.G. (1997). Strategic decision making: the influence of CEO experience and use of tacit knowledge. Journal of Managerial Issues 9(4): 454-467.

CABRERA, A., COLlins, W., SAlGADO, J. S. (2006). Determinants of individual engagement in knowledge sharing. International Journal of Human Resource Management 17(2): 254-264.

http://dx.doi.org/10.1080/09585190500404614

DEIBLOVÁ, M. (2005). Motivation as Management Tool. Praha: Linde.

DISMAN, M. (2008). Jak se vyrábí sociologická znalost. Praha: Karolinum.

EUCKER, T. (2007). Understanding the impact of tacit knowledge loss. Knowledge Management Review 10 (1): 10-13.

GOLDRATT, E. M. (2009). Isn't It Obvious? USA: North River Press.

GOSLING, S. D; RENTFROW, P. J; SWANN, W. B. (2003). A very brief measure of the big-five personality domains. Journal of Research in Personality 37(6): 504-528.

http://dx.doi.org/10.1016/S0092-6566(03)00046-1

HALDIN-HERRGARD, T. (2000). Difficulties in diffusion of tacit knowledge in organizations. Journal of Intellectual Capital 1(4): 357-365.

http://dx.doi.org/10.1108/14691930010359252

HARSH, O. K. (2009). Three dimensional KM and explicit knowledge reuse. Journal of Knowledge Management Practice 10(2): 1-10.

HACKMAN, J. R., OLDHAM, G. R. (1980). Work Redesign. Reading, MA: Addison-Wesley.

HAYES, N. (1998). Základy sociální psychologie. Praha: Portál.

JENKINS, A. K. (2009). Keeping the talent: understanding the needs of engineering and scientists in the defense acquisition workforce. Defense A $R$ Journal 4(1): 164-170.

JOHANNESSEN, J., OLSEN, B. (2003). Knowledge management and sustainable competitive advantages: the impact of dynamic contextual training. International Journal of Information Management 23(4): 277-289. http://dx.doi.org/10.1016/S02684012(03)00050-1

JOHN, O.P., NAUMANN, L.P., SOTO, C.J. (2008). Paradigm shift to the integrative big-five trait taxonomy: history, measurement, and conceptual issues. Handbook of Personality: Theory and Research. New York: Guilford Press, 114-158.

KACHAŇÁKOVÁ, A., STACHOVÁ, K. (2011). The level of education and development of employees in organisations operating in Slovakia. Scientia Agriculturae Bohemica 2011(2): 87-92.
KATCHER, B. L., SNYDER, A. (2007). 30 Reasons Employees Hate their Managers. New York: Amacom.

KOCIANOVÁ, R. (2010). Personální rízení a metody. Praha: Grada.

MEYER, J. P, ALLEN, N. J. (1991). A threecomponent conceptualization of organizational commitment. Human Resource Management Review 1(1): 61-89. 4822(91)90011-Z

http://dx.doi.org/10.1016/1053-

MILLER, J. (2007). Knowledge Management: How Organizations Manage Their Resources. USA: Xulon Press.

NENADÁL, J. (2001). Měření v systémech managementu jakosti. Praha: Management Press.

NONAKA, I., TAKEUCHI, H. (1995). The Knowledge Creating Company. New York: Oxford Press.

NONAKA, I. (1991). The knowledge creating company. Harward Business Review 69(6): 96-104.

PREVOT, F. (2008). Interfirm knowledge transfer methods. Journal of Knowledge Management 6(5): 37-60.

RAMLALL, S. J. (2004). A review of employee motivation theories and their implications for employee retention within organisations. The Journal of American Academy of Business 5(1): 52-63.

SHIH, H., CHIANG, Y. (2005). Strategy alignment between HRM, KM and corporate development. International Journal of Manpower 8(1): 5-19.

SOMAYA, D., WILLIAMSON, I. O. (2008). Rethinking the 'War for talent'. MIT Sloan Management Review 49(4): 29-34.

WONG N. W. (2009). The strategic skills of business continuity managers: putting business continuity management into corporate long-term planning. Journal of Business Continuity \& Emergency Planning 4(1): 62-68.

\section{Additional sources}

BOWES, B.J. (2010). A competitive employee market compels companies to manage high turnover. Available online at: <http://legacybowesgroup.com/component/content/article/43-retention/183-a-competitiveemployee-market-compels-companies-to-managehigh-turnover.html $>$.

HEATHFIELD, S.M. (2010) Keep your best: retention tips: retention in an improving job market. Available online at: <http://humanresources.about. com/cs/retention/a/turnover.htm>. 
REIß, CH. (2008). Fluktuation. Available online at: $<$ http://www.personaler-online.de/typo3/nc/personalthemen/suche-in-artikeln/detailansicht/artikel/fluktuation.html>.
ZAHORSKY, D. (2010). Fighting employee turnover costs: reduce employee turnover. Available online at: $<$ http://sbinformation.about.com/od/hiringfiring/a/ reduceturnover.htm>. 